But it also draws attention to some possibly significant relationships which either were not previously apparent or are different from those implied by the use of the $M_{\mathrm{s}}$ scale. For example, when $W_{0}$ is plotted against time for the period 1920-76 (for which the data are almost complete) it becomes clear that the annual average for the period 1920-65 (within which $W_{0}$ peaks) is more than an order of magnitude higher than that for the periods $1920-50$ and 1965-76. This picture is quite different from that based on $E$ calculated from $M_{\mathrm{s}}$, which shows a steady decrease since the mid$1940 \mathrm{~s}$. The significance of this difference becomes clear with the discovery that the $E$-from- $M_{\mathrm{s}}$ curve is very similar in shape to the corresponding time curve of the number $(N)$ of earthquakes with $M_{\mathrm{s}} \geqslant 7.0$. Since the $N$ curve is heavily biased in favour of moderate-to-large earthquakes, the proportion of events with $M_{\mathrm{s}}>8.0$ being small $(3.3 \%)$, the implication is that the $E$-from- $M_{\text {s }}$ curve is also biased in favour of moderate-to-large earthquakes, indicating that for great earthquakes the seismic wave energy calculated from $M_{\mathrm{s}}$ is indeed underestimated.

This being the case, it becomes clear from a comparison of the $W_{1}$ and $E$-from- $M_{\text {s }}$ curves that the number of, and the wave energy radiated by, moderate-to-large earthquakes decreased sharply just when the energy from great earthquakes increased sharply. Was this just a coincidence or was there a causal link there somewhere? The evidence suggests the latter. As Kanamori demonstrates, there is a remarkable correlation between the $W_{4}$ curve and the curve of Chandler Wobble amplitude, with $W_{\mathrm{n}}$ moving in the same way as, but slightly behind, the amplitude.
One possible explanation for this correlation is that an increase in Chandler Wobble amplitude, brought about by external (for example, atmospheric) forces, triggers worldwide seismic activity and accelerates plate motions, eventually leading to great platedecoupling earthquakes which so decrease intraplate and interplate stresses that moderate-to-large earthquake activity declines. On the other hand, the activity of great earthquakes could produce the Chandler Wobble, although this seems to be less likely. Then a third possibility is that the Chandler Wobble and great earthquakes have a common cause such as perturbations in the Earth's rotation. Whatever the explanation may be, the ancient controversey over the precise connection, if any, between earthquakes and Chandler Wobble has evidently been revived.
Loess is essentially a silty soil, widely believed to have been deposited by the wind and is of particular interest as the soil on which some of the earliest agriculture flourished. The aims of the Loess Commission have been to produce a map showing the distribution of loess in Europe and to untangle some of the stratigraphic problems presented by the thick loess sequences of central Europe. It was formed as a subcommission at the 1961 INQUA meeting in Warsaw and upgraded to full commission status at the 1969 Paris meeting. Julius Fink (Austria) was its first president and he has steered the commission to the virtual completion of its initial tasks (see Eiszeit. u. Gegenwart 27, 220; 1976). At Birmingham, progress on the loess map was reported by G. Haase (DDR); the western sheet is virtually complete and proof prints should be available by the end of 1977. The eastern sheet has been delayed by the lack of a suitable topographic base but with the help of I. P. Gerasimov (USSR) this difficulty has now been overcome. Details of the map scales and the data presented are given in a paper by Haase, Ruske (DDR) and Fink which will appear soon in Petermanns Geog. Mitt.

Fink reported on field trips since the last congress (Christchurch 1973); visits have been made to Germany (BRD, 1974), France (1975) and the Soviet Union (Ukraine and Moldavia, 1976). Now that the European problems have been tackled the commission is looking east to the Asian loesses and the 1976 trip to Soviet territory represents the first tentative

I. J. Smalley is a Lecturer in the Department of Civil Engineering at the University of Leeds.

\section{New look for Loess Commission}

\section{from I. J. Smalley}

Commission 4 of the International

Union of Quaternary Research (INQUA) met at Birmingham University on 16 and 23 August, 1977. The scope of the Loess Commission is to be expanded, and practical aspects of loess investigation will be emphasised.

move in that direction. The commission will also turn to the study of more practical aspects of loess and give some emphasis to irrigation problems and engineering and economic topics. New INQUA bye-laws require sweeping changes in the commission membership and advantage will be taken of this to reflect new interests (both topical and regional). The new president is Marton Pecsi (Hungary), Director of the Geographical Institute of the Academy of Sciences in Budapest; vice-president, B. Frenzel (BRD); secretary, O. Fränzle (BRD); and a group representing Europe: J-P. Lautridou (France), J. Fink (Austria), J. Macoun (Czechoslovakia), A. E. Dodonov (USSR) and I. J. Smalley (UK). R. V. Ruhe (USA) will coordinate activities in North America and $\mathbf{J}$. M. Bowler (Australia) will do the same for the Australasian and Pacific regions; there are eighteen corresponding members.

J. M. Bowler reported on the contacts between Australia and China. A group from the Australian National University has visited the classic loess regions of north China and returned with samples and Chinese loess literature. Important papers will be translated and published in English. In particular the major works by Liu Tung-sheng and his collaborators will be made available. Chinese investigators have visited Australia to look at acolian sediments in the central regions. There is no loess as such in Australia but the aeolian sediments have enough features in common to make comparative studies worthwhile. The contact at present is established at governmental level but the commission hopes to participate in studies of one of the world's most fascinating and still problematical (see News and Views 267, 484; 1977) loess deposits.

Pecsi rounded the meeting off with a personal view of new aims for the commission. He stressed the need for research into practical problems connected with loess and proposed that in the next phase of the commission's activities there should be some emphasis on foundation problems and related engineering topics, on problems of landscape deterioration in loess areas, and on problems of forecasting and planning for land use. Traditional activities should not be neglected however and it might be possible to investigate certain loess stratotypes very thoroughly-perhaps on an international basis. He proposed that the section at Paks in Hungary might receive the same intense study as that organised by Fink at Krems in Austria.

The next loess discussion will probably be in Jerusalem at the Sedimentological Congress in July 1978. D. H. Yaalon (Israel) will prove to doubters that desert loess exists. 